\title{
Ultrasonic, Volumetric and Isentropic Compressibility of Binary Mixtures of 1,4-Dioxane with Primary Alcohols at 303.15 K
}

\author{
Seema Agarwal, Dhirendra Kumar Sharma \\ Department of chemistry, Bundelkhand University, Jhansi, Jhansi, Utter Pradesh, India \\ Email: dhirendra.dr@rediffmail.com
}

How to cite this paper: Agarwal, S. and Sharma, D.K. (2021) Ultrasonic, Volumetric and Isentropic Compressibility of Binary Mixtures of 1,4-Dioxane with Primary Alcohols at $303.15 \mathrm{~K}$. Open Journal of Physical Chemistry, 11, 168-181. https://doi.org/10.4236/ojpc.2021.113010

Received: June 16, 2021

Accepted: July 31, 2021

Published: August 3, 2021

Copyright $\odot 2021$ by author(s) and Scientific Research Publishing Inc. This work is licensed under the Creative Commons Attribution International License (CC BY 4.0).

http://creativecommons.org/licenses/by/4.0/

\begin{abstract}
Density, viscosity and sound velocity of six binary liquid mixtures of methanol, ethanol, propanol, butanol, hexanol and octanol with 1,4-dioxane have been measured over the entire range of composition at temperature $303.15 \mathrm{~K}$. From the experimental densities, viscosities and sound velocity, the excess molar volume $\left(V^{E}\right)$, deviation in viscosity $(\Delta \eta)$ and deviation in isentropic compressibility $\left(\Delta K_{S}\right)$ have been calculated. The results have been used to discuss the nature and strength of intermolecular interactions in these mixtures.
\end{abstract}

\section{Keywords}

Density, Viscosity, Sound Velocity, Excess Molar Volume, Viscosity Deviation, Isentropic Compressibility Binary Mixtures, Alcohols

\section{Introduction}

The present paper is part of our ongoing research on the thermodynamic properties of binary liquid mixtures [1] containing 1,4-dioxane with 1-alkanol at 303.15 $\mathrm{K}$. Therefore their binary mixture properties are needed as a useful database in a variety of industrial applications [2] [3] [4] [5] [6]. Therefore, their interactions with different types of liquids such as 1,4-dioxane, methanol, ethanol, propanol, butanol, hexanol and octanol are important from a fundamental viewpoint. A wide range of important binary mixtures containing the above liquids have been studied by different authors [7] [8] [9] [10]. More over, to the best of our knowledge, no physical property data on the mixtures in the present study are available. This prompted us to undertake a study on the measurement of physical properties such as density $(\rho)$, viscosity $(\eta)$ and sound velocity $(u)$ at $303.15 \mathrm{~K}$. Using 
these data, the excess molar volume $(V E)$, deviations in viscosity $(\Delta \eta)$ and deviation in isentropic compressibility $\left(\Delta K_{s}\right)$ were calculated. The results are graphically presented. The excess properties values have been interpreted in terms of the nature of intermolecular interactions between constituent molecules of mixtures [11]-[19].

\section{Experimental}

\section{Materials and Method}

The chemicals (AR grade) employed were supplied by Merck. Chem. Ltd. India, Their purities (in mass percent) were 1,4-dioxane 99\%, methanol 99.27\%, ethanol 99.2\%, propanol 99.2\%, butanol 99.5\%, hexanol 99.3\% and octanol 99\%. All the chemicals were purified by a method given in the literature [20]. The purity of the liquids was also checked by measuring their densities, viscosities and sound velocities at $303.15 \mathrm{~K}$ and were in agreement with the literature values [21]-[29] are depicted in Table 1 .

All six binary liquid mixtures Viz. 1,4-dioxane + methanol, 1,4-dioxane + ethanol, 1,4-dioxane + propanol, 1,4-dioxane + butanol, 1,4-dioxane + hexanol and 1,4-dioxane + octanol were studied. Binary mixtures were prepared by weight covering the entire mole fraction range. The components of binary mixtures were injected by means of syringe in to the glass vials of sealed with rubber stopper in order to check evaporation losses during sample preparation. The weight of the sample was measured using electrical single pan analytical balance (K-roy instruments Pvt. Ltd. Varanasi (U.P.) India. The densities of pure liquids and their binary mixtures were measured $(303.15 \mathrm{~K})$ using a single-capillary pycnometer, made of borosil glass, having a bulb capacity of $30 \mathrm{~cm}^{3}$. The capillary, with graduated marks, had a uniform pore and could be closed by a well-fitted glass cap. The marks on the capillary were calibrated by using double-distilled water at $303.15 \mathrm{~K}$. The pycnometer was kept for about 30 minute in an electronically controlled thermostate water bath (MSI Goyal Scientific Meerut) $303.15 \pm 0.02 \mathrm{~K}$ and the position of the liquid level on the capillary was noted. The volume of the pycnometer at each mark was calculated by using the literature [30] value of the density of

Table 1. Physical properties of pure components at $303.15 \mathrm{~K}$.

\begin{tabular}{ccccccc}
\hline \multirow{2}{*}{ Component } & \multicolumn{2}{c}{$\rho\left(\mathrm{g}-\mathrm{m}^{-3}\right)$} & \multicolumn{2}{c}{$\eta(\mathrm{CP})$} & \multicolumn{2}{c}{$u\left(\mathrm{~m}-\mathrm{s}^{-1}\right)$} \\
\cline { 2 - 7 } & Observed & Literature & Observed & Literature & Observed & Literature \\
\hline 1,4-Dioxane & 1.0108 & $1.0229[25]$ & 1.0303 & $1.0690[24]$ & 1348.0 & $1322.3[50]$ \\
Methanol & 0.7840 & $0.7817[21]$ & 0.4949 & $0.5040[22]$ & 1084.0 & $1084.0[29]$ \\
Ethanol & 0.7720 & $0.7807[8]$ & 1.1399 & $1.3560[8]$ & 1141.0 & $1144.3[22]$ \\
Propanol & 0.8070 & $0.8003[28]$ & 1.5477 & $1.6626[22]$ & 1182.0 & $1182.6[22]$ \\
Butanol & 0.8040 & $0.8020[22]$ & 2.2045 & $2.2740[23]$ & 1196.0 & $1196.6[22]$ \\
Hexanol & 0.8128 & $0.8118[22]$ & 4.5642 & $4.5930[26]$ & 1298.0 & $1282.0[45]$ \\
Octanol & 0.8242 & $0.8187[27]$ & 7.8512 & $7.6630[26]$ & 1327.0 & $1330.8[27]$ \\
\hline
\end{tabular}


pure water at $303.15 \mathrm{~K}$. The volume these obtained is used to determine the density of the unknown liquid. The observed values of densities of pure 1,4-dioxane, methanol, ethanol, propanol, butanol, hexanol and octanol at $303.15 \mathrm{~K}$ were $1.0108,0.7840,0.7720,0.8070,0.8040,0.8128$ and $0.8242 \mathrm{~g} \cdot \mathrm{m}^{-3}$ which compare well with corresponding literature values of respectively. The ultrasonic velocities were measured using a multifrequency ultrasonic interferometer (Model F-80D, Mittal Enterprise, New Delhi) working at $3 \mathrm{MHz}$. The meter was calibrated with water and benzene at $303.15 \mathrm{~K}$. The measured values of ultrasonic velocities of pure 1,4-dioxane, methanol, ethanol, propanol, butanol, hexanol and octanol at $303.15 \mathrm{~K}$ were $1348,1084,1141,1182,1196,1298$ and $1327 \mathrm{~m} \cdot \mathrm{s}^{-1}$ respectively, which compare well with the corresponding literature values. The viscosity was measured by means of a suspended Ubbelohde type viscometer [31] calibrate was done at $303.15 \mathrm{~K}$ with double distilled water and purified methanol. An electronic digital stop watch with readability of \pm 0.01 was used for the flow time measurements. The measured values of viscosities of pure 1,4-dioxane, methanol, ethanol, propanol, butanol, hexanol and octanol at $303.15 \mathrm{~K}$ were 1.0303 , $0.4949,1.1399,1.5477,2.2045,4.5642$ and 7.8512 C.P. which compare well with the corresponding literature values. The mixtures were prepared by mixing known volumes of the pure liquids in air tight stoppered bottles. The weights were taken on a single pan electronic balance (Mittal Enterprises New Patel Nagar, New Delhi, India) accurate to $0.01 \mathrm{mg}$.

\section{Results and Discussion}

The experimental values of density, viscosity, and sound velocity data for mixtures of 1,4-dioxane 1) and primary alcohols 2) such as methanol, ethanol, propanol, butanol, hexanol and octanol were used to calculate the excess molar volume, viscosity deviations and isentropic compressibility. The results are presented in Table 2.

The excess molar volume is calculated using the equation ([32] [33])

$$
V^{E}=\left(M_{1} x_{1}+M_{2} x_{2}\right) / \rho_{\text {mix }}
$$

where $\rho_{\text {mix }}$ is the density of the mixture and $M_{1}, M_{2}, x_{1}, x_{2}, \rho_{1}$ and $\rho_{2}$ are the molecular weights, mole fraction and densities of pure components 1 and 2 respectively.

Quantitatively as per the absolute reaction rate theory [34] [35] the deviation of the viscosities $(\Delta \eta)$ from the ideal mixture values are calculated as [36]

$$
\Delta \eta=\eta_{\text {mix. }}-\left[x_{1} \eta_{1}+x_{2} \eta_{2}\right]
$$

where $\eta_{\text {mix. }}$ are the viscosity of the mixture and $\eta_{1}, \eta_{2}$ are the viscosity of pure components (1) and (2) respectively.

Isentropic compressibility $\left(K_{S}\right)$ and excess isentropic compressibility $\left(K_{S}^{E}\right)$ are calculated from the experiment density $(\rho)$ and sound velocity $(u)$ using the following equations [37] [38] [39] [40] [41]

$$
K_{S}=1 / u^{2} \rho
$$




$$
\Delta K_{S}=K_{S}-x_{1} K_{S 1}-x_{2} K_{S 2}
$$

where $K_{\mathcal{S}} K_{S 1}$ and $K_{S 2}$ are the isentropic compressibility of the mixture, pure component 1 and pure component 2 respectively.

We have calculated excess viscosity, excess molar volume and excess isentropic compressibility at $303.15 \mathrm{~K}$ for the binary mixture of 1,4-dioxane (1) with the primary alcohols (2). The variation of the excess properties over the entire range of compositions for the binary mixtures is depicted in Figures 1-3.

The value of excess molar volume was found to be negative value for 1,4-dioxane with methanol, ethanol and the positive value increase with increasing chain

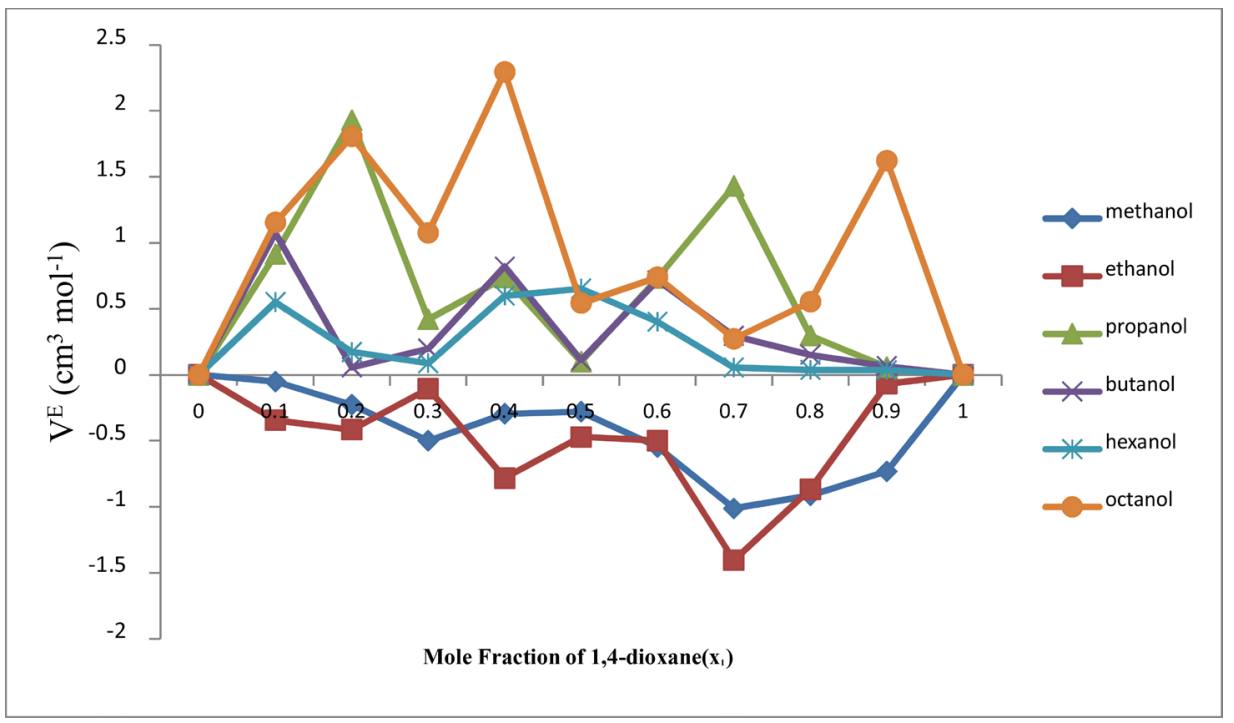

Figure 1. Plots of excess molar volume $\left(V^{E}\right)$ versus mole fraction of 1,4-dioxane $\left(x_{1}\right)$ at 303.15 $\mathrm{K}$ for binary mixtures of 1,4-dioxane with methanol, ethanol, propanol, butanol, hexanol and octanol.

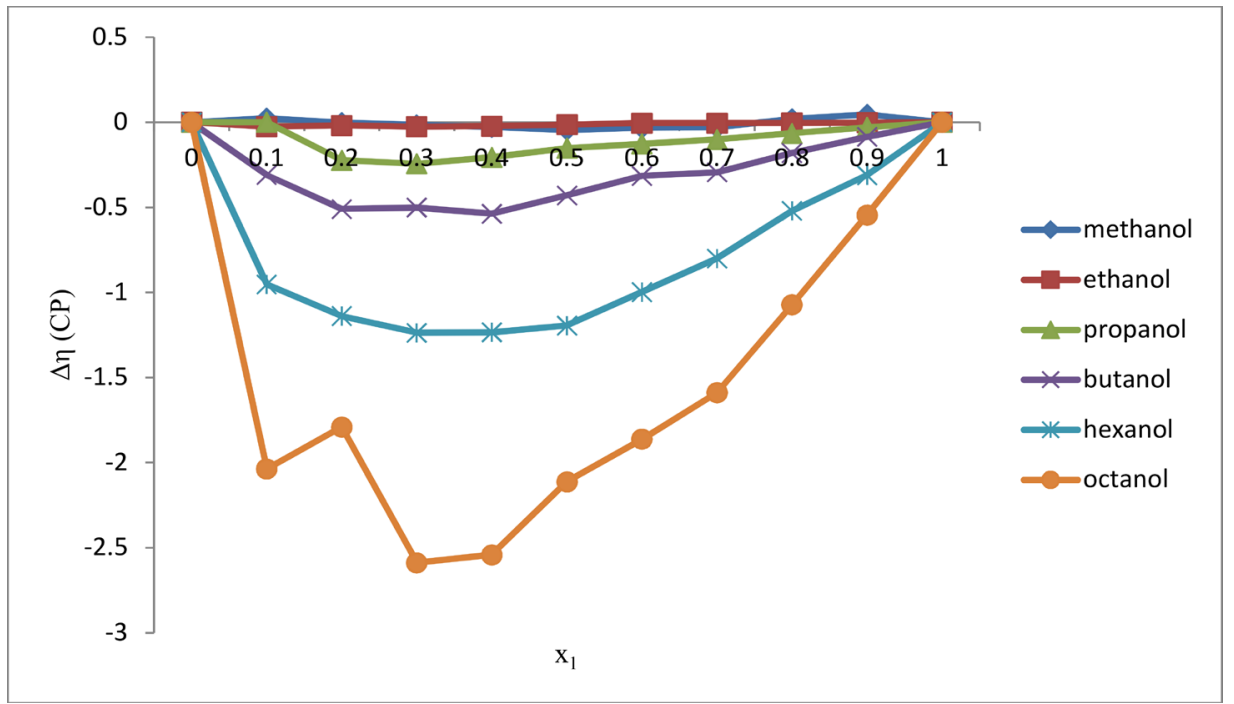

Figure 2. Plots of viscosity deviation $(\Delta \eta)$ versus mole fraction of 1,4-dioxane $\left(x_{1}\right)$ at $303.15 \mathrm{~K}$ for binary mixtures of 1,4-dioxane with methanol, ethanol, propanol, butanol, hexanol and octanol. 


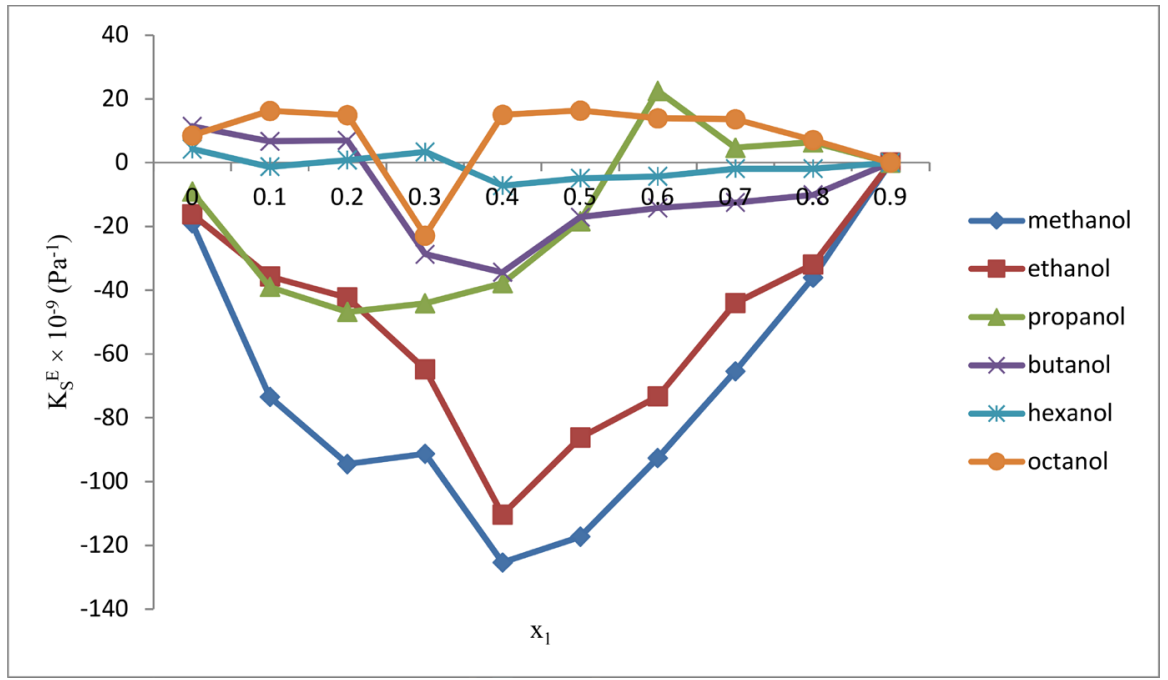

Figure 3. Plots of excess isentropic compressibility $\left(K_{S}^{E}\right)$ versus mole fraction of 1,4-dioxane at $303.15 \mathrm{~K}$ for binary mixtures of 1,4-dioxane with methanol, ethanol, propanol, butanol, hexanol and octanol.

length of the alcohols in Figure 1.

The trend it follows is $\mathrm{CH}_{3} \mathrm{OH}<\mathrm{C}_{2} \mathrm{H}_{5} \mathrm{OH}<\mathrm{C}_{3} \mathrm{H}_{7} \mathrm{OH}<\mathrm{C}_{4} \mathrm{H}_{9} \mathrm{OH}<\mathrm{C}_{5} \mathrm{H}_{11} \mathrm{OH}<$ $\mathrm{C}_{6} \mathrm{H}_{13} \mathrm{OH}<\mathrm{C}_{7} \mathrm{H}_{15} \mathrm{OH}<\mathrm{C}_{8} \mathrm{H}_{17} \mathrm{OH}$.

The negative molar volume values indicate the pressure of strong molecular interactions between the components of the mixtures. So many effects may contribute to the value of $V^{E}$, such as [42] [43] [44] (I) dipolar-interaction (II) interstitial accommodation of one component in to the other (III) possible hydrogen bond interactions between unlike molecules. The observed positive trends in $\left(V^{E}\right)$ values indicate that the effect due to the breaking up of self-associated structure of the components of the mixtures is dominant over the effect of H-bonding and dipole-dipole interaction between unlike molecule. The $V^{E}$ values increase in the sequence butanol $<$ hexanol $<$ octanol which also reflects the decreasing strength of interaction between unlike molecules in the mixture. As the size of the alkyl group increases from propanol to octanol, the steric hindrance also increases. Thus the extent of positive deviation (Figure 1) supports our view [45].

A correlation between the sign of $\Delta \eta$ and $V^{E}$ has been observed for a number of binary solvent system ([46] [47]) i.e. $\Delta \eta$ is negative when $V E$ is positive and vice-versa. In general for systems where dispersion and dipolar interactions are operating, $\Delta \eta$ values are found to be negative, whereas charge transfer and hydrogen bonding interactions lead to the formation of complex species between unlike molecules.

The calculated $\Delta K_{S}$ values for the binary liquid mixture listed in Table 3. The change of this property has been shown in Figure 3. The $\Delta K_{S}$ values are negative over the entire mole fraction range and become more negative with increasing the mole fraction of second component for all binary mixtures. These results can be explained in term of molecular interactions and structured effects.

The variation of $\Delta K_{S}$ with volume fraction of 1,4-dioxane $X_{1}$ is represent in 
Table 2. Experimental Results for the binary Liquid Mixtures of 1,4-Dioxane (1) + Primary alcohols (2) at $303.15 \mathrm{~K}$.

\begin{tabular}{|c|c|c|c|c|}
\hline $\begin{array}{l}\text { Mole fraction } \\
\text { Dioxane }\left(x_{1}\right)\end{array}$ & $\rho\left(\mathrm{g} \cdot \mathrm{m}^{-3}\right)$ & $\eta(\mathrm{CP})$ & $\Delta \eta(\mathrm{CP})$ & $V E\left(\mathrm{~cm}^{3} \cdot \mathrm{mole}^{-1}\right)$ \\
\hline \multicolumn{5}{|c|}{ 1,4-Dioxane + Methanol } \\
\hline 0.0000 & 0.7840 & 0.4949 & 0.0000 & 0.0000 \\
\hline 0.0977 & 0.8274 & 0.5704 & +0.0232 & -0.0505 \\
\hline 0.2004 & 0.8669 & 0.6005 & -0.0015 & -0.2259 \\
\hline 0.2867 & 0.8969 & 0.6339 & -0.0143 & -0.4987 \\
\hline 0.3801 & 0.9171 & 0.6703 & -0.0280 & -0.2947 \\
\hline 0.4985 & 0.9422 & 0.7168 & -0.0449 & -0.2794 \\
\hline 0.5919 & 0.9631 & 0.7802 & -0.0315 & -0.5467 \\
\hline 0.7086 & 0.9877 & 0.8441 & -0.0301 & -1.0120 \\
\hline 0.8002 & 0.9987 & 0.9426 & +0.0193 & -0.9140 \\
\hline 0.9036 & 1.0089 & 1.0244 & +0.0457 & -0.7305 \\
\hline 1.0000 & 1.0108 & 1.0303 & 0.0000 & 0.0000 \\
\hline \multicolumn{5}{|c|}{ 1,4-Dioxane + Ethanol } \\
\hline 0.0000 & 0.7720 & 1.1399 & 0.0000 & 0.0000 \\
\hline 0.0988 & 0.8094 & 1.1038 & -0.0251 & -0.3437 \\
\hline 0.2046 & 0.8426 & 1.0986 & -0.0187 & -0.4155 \\
\hline 0.2996 & 0.8652 & 1.0814 & -0.0255 & -0.1063 \\
\hline 0.3974 & 0.8990 & 1.0740 & -0.0222 & -0.7812 \\
\hline 0.5022 & 0.9201 & 1.0710 & -0.0137 & -0.4701 \\
\hline 0.5950 & 0.9410 & 1.0697 & -0.0049 & -0.4986 \\
\hline 0.6900 & 0.9720 & 1.0593 & -0.0049 & -1.4042 \\
\hline 0.7993 & 0.9862 & 1.0485 & -0.0037 & -0.8659 \\
\hline 0.8934 & 0.9935 & 1.0406 & -0.0013 & -0.0668 \\
\hline 1.0000 & 1.0108 & 1.0303 & 0.0000 & 0.0000 \\
\hline \multicolumn{5}{|c|}{ 1,4-Dioxane + Propanol } \\
\hline 0.0000 & 0.8070 & 1.5477 & 0.0000 & 0.0000 \\
\hline 0.1000 & 0.8206 & 1.4964 & +0.0005 & +0.9139 \\
\hline 0.1226 & 0.8407 & 1.2610 & -0.2232 & +1.9297 \\
\hline 0.2982 & 0.8700 & 1.1498 & -0.2435 & +0.4208 \\
\hline 0.4057 & 0.8893 & 1.1319 & -0.2058 & +0.7359 \\
\hline 0.5043 & 0.9167 & 1.1274 & -0.1515 & +0.0990 \\
\hline 0.6025 & 0.9290 & 1.1097 & -0.1262 & +0.7335 \\
\hline 0.6941 & 0.9558 & 1.0881 & -0.1004 & +1.4319 \\
\hline 0.7962 & 0.9708 & 1.0711 & -0.0645 & +0.2982 \\
\hline 0.8992 & 0.9924 & 1.0534 & -0.0290 & +0.0583 \\
\hline
\end{tabular}




\section{Continued}

\begin{tabular}{|c|c|c|c|c|}
\hline 1.0000 & 1.0108 & 1.0303 & 0.0000 & 0.0000 \\
\hline \multicolumn{5}{|c|}{ 1,4-Dioxane + Butanol } \\
\hline 0.0000 & 0.8040 & 2.2045 & 0.0000 & 0.0000 \\
\hline 0.0973 & 0.8136 & 1.7804 & -0.3097 & +1.0740 \\
\hline 0.1975 & 0.8425 & 1.4627 & -0.5096 & +0.0580 \\
\hline 0.3044 & 0.8626 & 1.3458 & -0.5011 & +0.1987 \\
\hline 0.4048 & 0.8769 & 1.1934 & -0.5367 & +0.8202 \\
\hline 0.4944 & 0.9022 & 1.1939 & -0.4299 & +0.1106 \\
\hline 0.5976 & 0.9174 & 1.1879 & -0.3147 & +0.7156 \\
\hline 0.6862 & 0.9402 & 1.1044 & -0.2941 & +0.2949 \\
\hline 0.7907 & 0.9639 & 1.0953 & -0.1805 & +0.1522 \\
\hline 0.8909 & 0.9863 & 1.0728 & -0.0855 & +0.0650 \\
\hline 1.0000 & 1.0108 & 1.0303 & 0.0000 & 0.0000 \\
\hline \multicolumn{5}{|c|}{ 1,4-Dioxane + Hexanol } \\
\hline 0.0000 & 0.8128 & 4.5642 & 0.0000 & 0.0000 \\
\hline 0.0910 & 0.8219 & 3.2904 & -0.9518 & +0.5509 \\
\hline 0.1948 & 0.8400 & 2.7369 & -1.1385 & +0.1738 \\
\hline 0.2984 & 0.8572 & 2.2727 & -1.2368 & +0.0883 \\
\hline 0.4043 & 0.8714 & 1.9013 & -1.2337 & +0.59964 \\
\hline 0.4543 & 0.8799 & 1.7643 & -1.1943 & +0.6533 \\
\hline 0.6028 & 0.9107 & 1.4365 & -0.9971 & +0.4033 \\
\hline 0.6997 & 0.9346 & 1.2914 & -0.7999 & +0.0548 \\
\hline 0.8018 & 0.9584 & 1.2103 & -0.5202 & +0.0373 \\
\hline 0.8883 & 0.9800 & 1.1144 & -0.3103 & +0.0356 \\
\hline 1.0000 & 1.0108 & 1.0303 & 0.0000 & 0.0000 \\
\hline \multicolumn{5}{|c|}{ 1,4-Dioxane + Octanol } \\
\hline 0.0000 & 0.8242 & 7.8512 & 0.0000 & 0.0000 \\
\hline 0.0978 & 0.8284 & 5.1466 & -2.0374 & +1.1543 \\
\hline 0.2065 & 0.8370 & 4.6513 & -1.7911 & +1.8065 \\
\hline 0.2981 & 0.8529 & 3.2294 & -2.5883 & +1.0755 \\
\hline 0.4027 & 0.8595 & 2.5625 & -2.5414 & +2.2951 \\
\hline 0.4922 & 0.8852 & 2.3806 & -2.1126 & +0.5428 \\
\hline 0.6006 & 0.9030 & 1.8916 & -1.8623 & +0.7398 \\
\hline 0.6988 & 0.9266 & 1.4950 & -1.5891 & +0.2733 \\
\hline 0.7961 & 0.9464 & 1.3490 & -1.0720 & +0.5537 \\
\hline 0.8974 & 0.9759 & 1.1845 & -0.5448 & +1.6229 \\
\hline 1.0000 & 1.0108 & 1.0303 & 0.0000 & 0.0000 \\
\hline
\end{tabular}


Table 3. Speeds of sound $(u)$, Isentropic Compressibility $\left(K_{S}\right)$ and Excess Isentropic Compressibility $\left(K_{S}^{E}\right)$ of Binary Mixtures of Various Composition (Mole Fraction) at $303.15 \mathrm{~K}$

\begin{tabular}{|c|c|c|c|}
\hline $\begin{array}{l}\text { Mole fraction } \\
\text { Dioxane }\left(x_{1}\right)\end{array}$ & $u\left(\mathrm{~m}-\mathrm{s}^{-1}\right)$ & $K_{S} \times 10^{-9}\left(\mathrm{~Pa}^{-1}\right)$ & $K_{S}^{E} \times 10^{-9}\left(\mathrm{~Pa}^{-1}\right)$ \\
\hline \multicolumn{4}{|c|}{ 1,4-Dioxane + Methanol } \\
\hline 0.0000 & 1084.0 & 1085.4 & 0.0 \\
\hline 0.0977 & 1092.0 & 1013.4 & -19.0 \\
\hline 0.2004 & 1130.0 & 903.3 & -73.5 \\
\hline 0.2867 & 1155.0 & 835.7 & -94.5 \\
\hline 0.3801 & 1176.0 & 788.3 & -91.3 \\
\hline 0.4985 & 1240.0 & 690.2 & -125.4 \\
\hline 0.5919 & 1266.0 & 647.8 & -117.3 \\
\hline 0.7086 & 1289.0 & 609.3 & -92.6 \\
\hline 0.8002 & 1306.0 & 587.0 & -65.4 \\
\hline 0.9036 & 1330.0 & 560.3 & -36.1 \\
\hline 1.0000 & 1348.0 & 544.4 & 0.0 \\
\hline \multicolumn{4}{|c|}{ 1,4-Dioxane + Ethanol } \\
\hline 0.0000 & 1141.0 & 994.9 & 0.0 \\
\hline 0.0988 & 1150.0 & 934.1 & -16.2 \\
\hline 0.2046 & 1170.0 & 866.9 & -35.7 \\
\hline 0.2996 & 1189.0 & 817.5 & -42.3 \\
\hline 0.3974 & 1217.0 & 751.0 & -64.8 \\
\hline 0.5022 & 1285.0 & 658.1 & -110.4 \\
\hline 0.5950 & 1288.0 & 640.5 & -86.2 \\
\hline 0.6900 & 1298.0 & 610.6 & -73.3 \\
\hline 0.7993 & 1310.0 & 590.8 & -44.0 \\
\hline 0.8934 & 1340.0 & 560.5 & -31.9 \\
\hline 1.0000 & 1348.0 & 544.4 & 0.0 \\
\hline \multicolumn{4}{|c|}{ 1,4-Dioxane + Propanol } \\
\hline 0.0000 & 1182.0 & 886.8 & 0.0 \\
\hline 0.1000 & 1202.0 & 843.4 & -9.1 \\
\hline 0.1226 & 1215.0 & 805.7 & -39.0 \\
\hline 0.2982 & 1248.0 & 737.9 & -46.8 \\
\hline 0.4057 & 1264.0 & 703.7 & -44.1 \\
\hline 0.5043 & 1270.0 & 676.3 & -37.8 \\
\hline 0.6025 & 1275.0 & 662.1 & -18.4 \\
\hline 0.6941 & 1284.0 & 671.7 & +22.5 \\
\hline 0.7962 & 1290.0 & 618.9 & +4.7 \\
\hline 0.8992 & 1312.0 & 585.3 & +6.4 \\
\hline
\end{tabular}




\section{Continued}

\begin{tabular}{lccc}
\hline 1.0000 & 1348.0 & 544.4 & 0.0 \\
\hline 0.0000 & 11,4 -Dioxane + Butanol & \\
0.0973 & 1196.0 & 869.5 & 0.0 \\
0.1975 & 1203.0 & 849.2 & +11.4 \\
0.3044 & 1209.0 & 812.0 & +6.7 \\
0.4048 & 1221.0 & 777.5 & +7.0 \\
0.4944 & 1268.0 & 709.2 & -28.7 \\
0.5976 & 1282.0 & 674.3 & -34.4 \\
0.6862 & 1287.0 & 658.0 & -17.1 \\
0.7907 & 1297.0 & 632.2 & -14.2 \\
0.8909 & 1315.0 & 599.9 & -12.5 \\
1.0000 & 1334.0 & 569.7 & -10.1 \\
\hline
\end{tabular}

\begin{tabular}{cccc}
\hline \multicolumn{4}{c}{1,4 -Dioxane + Hexanol } \\
\hline 0.0000 & 1298.0 & 730.2 & 0.0 \\
0.0910 & 1302.0 & 717.6 & +4.3 \\
0.1948 & 1311.0 & 692.6 & -1.3 \\
0.2984 & 1314.0 & 675.6 & +0.8 \\
0.4043 & 1320.0 & 658.5 & +3.4 \\
0.4543 & 1334.0 & 638.5 & -7.2 \\
0.6028 & 1338.0 & 613.3 & -4.9 \\
0.6997 & 1340.0 & 595.8 & -4.3 \\
0.8018 & 1342.0 & 579.3 & -1.9 \\
0.8883 & 1346.0 & 563.2 & -1.9 \\
1.0000 & 1348.0 & 544.4 & 0.0 \\
\hline
\end{tabular}

\begin{tabular}{lccc}
\hline \multicolumn{4}{c}{1,4 -Dioxane + Octanol } \\
\hline 0.0000 & 1327.0 & 689.0 & 0.0 \\
0.0978 & 1329.0 & 683.4 & +8.5 \\
0.2065 & 1330.0 & 675.3 & +16.2 \\
0.2981 & 1332.0 & 660.8 & +14.9 \\
0.4027 & 1334.0 & 653.8 & -22.9 \\
0.4922 & 1336.0 & 632.8 & +15.0 \\
0.6006 & 1338.0 & 618.5 & +16.3 \\
0.6988 & 1339.0 & 601.9 & +13.9 \\
0.7961 & 1341.0 & 587.5 & +13.6 \\
0.8974 & 1345.0 & 566.4 & +7.1 \\
1.0000 & 1348.0 & 544.4 & 0.0 \\
\hline
\end{tabular}


Figure 3. Kiyohara and Benson [48] have suggested that $\Delta K_{S}$ is the result of several opposing effects. Strong molecular interactions occur through charge transfer, dipole-induced dipole and dipole-dipole interaction [49], interstitial accommodation and orientation ordering all lead to a more compact structure making $\Delta K_{S}$ negative, whereas breakup of the alkanol structure trends to make $\Delta K_{S}$ positive. The magnitudes of the various contributions depend mainly on the relative molecular size of the components.

\section{Conclusion}

Thus paper reported the densities, viscosities and sound velocity of six pure methanol, ethanol, propanol, butanol, hexanol and octanol and mixture at $303.15 \mathrm{~K}$ over the entire range of mole fraction. After a thorough study of the behavior of primary alcohols and 1,4-dioxane we get a clear idea about the type and amount of molecular interactions between the components. The study of excess properties along with the speed of sound has been found to very useful in understanding the nature of the interactions within binary liquid mixtures. These excess properties obtained from the correlating equations have also provided the very important and useful information.

\section{Acknowledgments}

The authors are very much thankful to the Dean Science, Head of the Department of Chemistry, Bundelkhand University, Jhansi for proving the facilities for Research work.

\section{Conflicts of Interest}

The authors declare no conflicts of interest regarding the publication of this paper.

\section{References}

[1] Ansari, N.H., Trivedi, A., Sharma, D.K. and Chandra, P. (2014) Refractometric Studies on Molecular Interactions in Six Binary Liquid Mixtures. Open Journal of Physical Chemistry, 4, 1-5. https://doi.org/10.4236/ojpc.2014.41001

[2] Aralaguppi, M.I., Jadar, C.V. and Aminabhavi, T.M. (1996) Density, Refractive Index, Viscosity, and Speed of Sound in Binary Mixtures of 2-Ethoxyethanol with Dioxane, Acetonitrile, and Tetrahydrofuran at (298.15, 303.15, and 308.15) K. Journal of Chemical \& Engineering Data, 41, 1307-1310. https://doi.org/10.1021/je960133t

[3] Nobandegani, F.F. and Roeintan, A. (2019) Volumetric and Ultrasonic Study of Mixtures of Benzyl Alcohol with 1-Propanol, 2-Propanol, and 1,2-Propandiol, 1,3Propandiol and T-Butanol. American Journal of Mechanics and Applications, 7, 88-100. www.sciencepublishinggroup.com/journal/index?journalid=621 https://doi.org/10.11648/j.ajma.20190704.12

[4] Nayak, J.N., Aralaguppi, M.I. and Aminabhavi, T.M. (2003) Density, Viscosity, Refractive Index, and Speed of Sound in the Binary Mixtures of 1, 4-Dioxane + Ethanediol, + Hexane, + Tributylamine, or + Triethylamine at $(298.15,303.15$, and 308.15) K. Journal of Chemical \& Engineering Data, 48, 1152-1156. 
https://doi.org/10.1021/je030107c

[5] Nayak, J.N., Aralaguppi, M.I., Naidu, B.V.K. and Aminabhavi, T.M. (2003) Thermodynamic Properties of water + Tetrahydrofuran and Water + 1,4-Dioxane Mixtures at $(303.15,313.15$ and 323.15) K. Journal of Chemical \& Engineering Data, 49, 468-474. https://doi.org/10.1021/je030196t

[6] Joshi, S.S. and Aminabhavi, T.M. (1990) Excess Volumes of Binary Mixtures of Anisole with Bromobenzene, O-Dichlorobenzene, O-Chloroaniline and P-Dioxane at 298.15, 303.15, 308.15 and 313.15 K. Fluid Phase Equilibria, 60, 319-326. https://doi.org/10.1016/0378-3812(90)85061-E

[7] Rodriguez, A., Canosa, J. and Tojo, J. (1999) Physical Properties of the Ternary Mixture Dimethyl Carbonate + Methanol + Benzene and Its Corresponding Binaries at 298.15 K. Journal of Chemical \& Engineering Data, 44, 1298-1303. https://doi.org/10.1021/je990144x

[8] Rodriguez, A., Canosa, J. and Tojo, J. (2001) Physical Properties and Liquid-Liquid Equilibrium and Physical Properties of the Ternary Mixture (Dimethyl Carbonate + Methanol + Cyclohexane) at 298.15 K. Journal of Chemical \& Engineering Data, 46, 846-850. https://doi.org/10.1021/je000180s

[9] Canosa, J., Rodriguez, A. and Tojo, J. (2001) Physical Properties and Liquid-Liquid Equilibrium of the Ternary Mixture (Dimethyl Carbonate + Methanol + Hexane) at 298.15 K. Journal of Chemical \& Engineering Data, 46, 184-187. https://doi.org/10.1021/je000180s

[10] Hasan, M., Hiray, A.P., Ujjan, B.K., Shirude, D.F., Kurhe, K.J. and Sawant, A.B. (2011) Density, Viscosities, Speeds of Sound, FT-IR and ${ }^{1} \mathrm{H}-\mathrm{NMR}$ Studies of Binary Mixtures of $n$-Butyl Acetate with Ethanol, Propanol-1-ol, Butan-1-ol and Pentan-1-ol at 298.15, 303.15, 308.15 and 313.15 K. Journal of Solution Chemistry, 40, 415-429. https://doi.org/10.1007/s10953-011-9657-7

[11] Nikam, P.S., Shirsat, L.N. and Hasan, M. (1998) Density and Viscosity Studies of Binary Mixtures of Acetonitrile with Methanol, Ethanol, Propan-1-ol, Propan-2-ol, Butan-1-ol, 2-Methylpropan-1-ol, and 2-Methylpropan-2-ol at (298.15, 303.15, 308.15, and 313.15) K. Journal of Chemical \& Engineering Data, 43, 732-737. https://doi.org/10.1021/je980028e

[12] Aminabhavi, T.M. and Gopalakrishna, B. (1995) Density, Viscosity, Refractive Index, and Speed of Sound in Aqueous Mixtures of N,N-Dimethylformamide, Dimethyl Sulfoxide, N,N-Dimethylacetamide, Acetonitrile, Ethylene Glycol, Diethylene Glycol, 1,4-Dioxane, Tetrahydrofuran, 2-Methoxyethanol, and 2-Ethoxyethanol at 298.15 K. Journal of Chemical \& Engineering Data, 40, 856-861.

https://doi.org/10.1021/je00020a026

[13] Ogawa, H. and Murakami, S. (1987) Excess Volumes, Isentropic Compressions, and Isobaric Heat Capacities for Methanol Mixed with Other Alkanols at $25^{\circ} \mathrm{C}$. Journal of Solution Chemistry, 16, 315-326.

https://link.springer.com/article/10.1007/BF00646123\#citeas https://doi.org/10.1007/BF00646123

[14] Jimenez, E., Cabanas, M., Segade, L., Garcia-Garabal, S. and Casas, H. (2001) Excess Volume, Changes of Refractive Index and Surface Tension of Binary 1,2-Ethanediol + 1-Propanol or 1-Butanol Mixtures at Several Temperatures. Fluid Phase Equilibria, 180, 151-164. https://doi.org/10.1016/S0378-3812(00)00519-7

[15] Zarei, H.A., Asadi, S. and IIukhani, H. (2008) Temperature Dependence of the Volumetric Properties of Binary Mixtures of (1-Propanol, 2-Propanol and 1,2-Propanediol) at Ambient Pressure (81.5 kPa). Journal of Molecular Liquids, 141, 25-30. 
https://doi.org/10.1016/j.molliq.2008.02.006

[16] Zorebski, E. and Luboweiecka-Kostka, B. (2009) Thermodynamic and Transport Properties of (1,2-Ethanediol + 1-Nonanol) at Temperatures from (298.15 to 313.15) K. The Journal of Chemical Thermodynamics, 41, 197-204. https://doi.org/10.1016/j.jct.2008.09.018

[17] Zorebski, E., Geppert-Rybezynska, M. and Maciej, B. (2010) Densities, Speeds of Sound, and Isentropic Compressibilities for Binary Mixtures of 2-Ethyl-1-hexanol with 1-Pentanol, 1-Heptanol, or 1-Nonanol at the Temperature 298.15 K. Journal of Chemical \& Engineering Data, 55, 1025-1029. https://doi.org/10.1021/je9004933

[18] Bravo-Sanchez, M.G., Iglesias-silva, G.A. and Estrada Baltazar, A. (2010)Densities and Viscosities of Binary Mixtures of $n$-Butanol with 2-Butanol, Isobutanol, and tert-Butanol from (303.15 to 343.15) K. Journal of Chemical \& Engineering Data, 55, 362. https://doi.org/10.1021/je900722m

[19] Papari, M.M., Ghodrati, H., Fadaei, F., Sadeghi, R., Behrouz, S. and Soltani Rad, M.N. (2013) Volumetric and Ultrasonic Study of Mixtures of 2-Phenylethanol with 1-Butanol, 2-Butanol, and 2-Methyl-1-Butanol at $\mathrm{T}=(298.15-323.15) \mathrm{K}$ and Atmospheric Pressure: Measurement and Prediction. Journal of Molecular Liquids, 180,121-128. https://doi.org/10.1016/j.molliq.2012.12.037

[20] Vogel, A.I. (1989) Text Book of Practical Organic Chemists. 5th Edition, Longmans Green, London.

[21] Nikam, P.S., Mahale, T.R. and Hasan, M. (1996) Density and Viscosity of Binary Mixtures of Ethyl Acetate with Methanol, Ethanol, Propan-1-ol, Propan-2-ol, Butan-1-ol, 2-Methylpropan-1-ol, and 2-Methylpropan-2-ol at $(298.15,303.15$, and 308.15) K. Journal of Chemical \& Engineering Data, 41, 1055-1058. https://doi.org/10.1021/je960090g

[22] Roy, M.N., Sinka, A. and Biswajit, S. (2005) Excess Molar Volumes, Viscosity Deviations and Isentropic Compressibility of Binary Mixtures Containing 1,3-Dioxolane and Monoalcohols at 303.15 K. Journal of Solution Chemistry, 34, 1311-1325. https://link.springer.com/article/10.1007/s10953-005-8022-0\#citeas https://doi.org/10.1007/s10953-005-8022-0

[23] Kadam, B.U., Hiray, P.A., Sawant, B.A. and Hasan, M. (2006) Densities, Viscosities, and Ultrasonic Velocity Studies of Binary Mixtures of Chloroform with Propan-1-ol and Butan-1-ol at (303.15 and 313.15) K. Journal of Chemical \& Engineering Data, 51, 60-63. https://doi.org/10.1021/je050169y

[24] Nayak, J.N., Aralaguppi, M.I. and Aminabhavi, T.M. (2003) Density, Viscosity, Refractive Index, and Speed of Sound in the Binary Mixtures of 1,4-Dioxane + Ethyl Acetoacetate, + Diethyl Oxalate, + Diethyl Phthalate, or + Dioctyl Phthalate at 298.15, 303.15, and 308.15 K. Journal of Chemical \& Engineering Data, 48, 1489-1494. https://doi.org/10.1021/je0301489

[25] Baragi, J.G., Aralaguppi, M.I. and Aminabhavi, T.M. (2005) Density, Viscosity, Refractive Index, and Speed of Sound for Binary Mixtures of 1, 4-Dioxane with Different Organic Liquids at $(298.15,303.15$, and 308.15) K. Journal of Chemical \& Engineering Data, 50, 917-923. https://doi.org/10.1021/je049609w

[26] Al-Kandary, A.J., Al-Jimaz, A.S. and Abdul-Latif, A.M. (2009) Densities, Viscosities, Speeds of Sound and Refractive Indices of Binary Mixtures of Tetrahydrofuran with 1-Hexanol, 1-Heptanol, 1-Octanol, 1-Nonanol and 1-Decanol at 298.15, 303.15, 308.15 and 313.15 K. Physics and Chemistry of Liquid, 47, 210-224.

https://doi.org/10.1080/00319100802123152

[27] Dubey, G.P. and Sharma, M. (2008) Excess Volumes, Densities, Speeds of Sound, 
and Viscosities for the Binary Systems of 1-Octanol with Hexadecane and Squalane at (298.15, 303.15 and 308.15) K. International Journal of Thermophysics, 29, 1361-1375. https://link.springer.com/article/10.1007/s10765-008-0491-0\#citeas https://doi.org/10.1007/s10765-008-0491-0

[28] Elangovan, S. and Mullainathan, S. (2013) Ultrasonic Studies of Intermolecular Interaction in Binary Mixture of $n$-Methyl Formate with 1-Propanol at Various Temperatures. Indian Journal of Physics, 87, 659-664.

https://link.springer.com/article/10.1007/s12648-013-0288-2\#citeas https://doi.org/10.1007/s12648-013-0288-2

[29] Yasmin, M., Singh, K.P., Parveen, S., Gupta, M. and Shukla, J.P. (2009) Thermoacoustical Excess Properties of BinaryLiquid Mixtures-A Comparative Experimental and Theoretical Study. Acta Physica Polonica A, 115, 890-900.

http://przyrbwn.icm.edu.pl/APP/PDF/115/a115z508.pdf https://doi.org/10.12693/APhysPolA.115.890

[30] Stokes, R.H. (1965) Solutions of Nonelectrolytes. Pergamon Press, Oxford.

[31] Suindells, J.F. and Godfrey, T.B. (1952) Absolute Viscosity of water at $20^{\circ} \mathrm{C}$. Journal of Research of the National Bureau of Standards, 48, 1.

[32] Nikam, P.S., Shirsat, L.N. and Hasan, M. (2000) Densities and Viscosities of Binary Mixtures of Acetonitrile with Alkanols (C5, C6, C7, C8, C10) at 298.15, 303.15, 308.15K. Journal of the Indian Chemical Society, 77, 244.

[33] Quin, A.W., Hoffmann, D.F. and Munk, P. (1992) Excess Volumes of Mixtures of Alkanes with Carbonyl Compounds. Journal of Chemical and Engineering Data, 37, 55-61. https://doi.org/10.1021/je00005a018

[34] Roy, M.N., Gurung, B.B. and Choudhury, A. (2004) Thermodynamic and Transport Behavior of Nonaqueous Binary Mixtures of Benzene with Carbon Tetra Choloride and Chloroform at Different Temperatures. Journal of the Indian Chemical Society, 81, 330-334.

[35] Glasstone, S., Laidler, K.J. and Eyring, H. (1941) The Theory of Rate Process. McGraw-Hill, New York, 514.

http://www.sidalc.net/cgi-bin/wxis.exe/?IsisScript=agrono.xis\&method=post\&form $\underline{\text { ato }}=2 \&$ cantidad $=1$ \&expresion $=\mathrm{mfn}=001365$

[36] Gill, D.S., Kaur, T.S., Kaur, H., Joshi, I.M. and Singh, J. (1993) Ultrasonic Velocity, Permittivity, Density, Viscosity and Proton Nuclear Magnetic Resonance Measurements of Binary Mixtures of Benzonitrile with Organic Solvents. Journal of the Chemical Society, Faraday Transactions, 89, 1737-1740.

[37] Lafuente, C., Giner, B., Villares, A., Gascon, I. and Cea, P. (2004) Speeds of Sound and Isentropic Compressibilities of Binary Mixtures Containing Cyclic Ethers and Haloalkanes at 298.15 and 313.15 K. International Journal of Thermophysics, 25, 1735-1746. https://link.springer.com/article/10.1007/s10765-004-7732-7\#citeas https://doi.org/10.1007/s10765-004-7732-7

[38] Douheret, G., Pal, A. and Davis, M.I. (1990) Ultrasonic Speeds and Isentropic Functions of a (2-Alkoxy Ethanol + Water ) at $298.15 \mathrm{~K}$. The Journal of Chemical Thermodynamics, 22, 1. https://linkinghub.elsevier.com/retrieve/pii/002196149090036P

[39] Artigas, H., Lafuente, C., Lopez, M.C., Royo, F.M. and Urieta, J.S. (2001) Calorimetric Behaviour of Primary Bromobutanes with Isomeric Butanols. Zeitschrift für Physikalische Chemie, 215, 933-942.

https://www.degruyter.com/document/doi/10.1524/zpch.2001.215.7.933/html https://doi.org/10.1524/zpch.2001.215.7.933

[40] Gascon, I., Martin, S., Cea, P., Lopez, M.C. and Royo, F.M. (2002) Density and 
Speed of Sound for Binary Mixtures of a Cyclic Ether with a Butanol Isome. Journal of Solution Chemistry, 31, 905-915.

https://link.springer.com/article/10.1023/A:1021467806352\#citeas https://doi.org/10.1023/A:1021467806352

[41] Kimura, F., Treszczanowicz, A., Halpin, C. and Benson, G. (1983) Excess Volumes and Ultrasonic Speeds for (di- $n$-Propylether $+n$-Heptane). The Journal of Chemical Thermodynamics, 15, 503-510. https://doi.org/10.1016/0021-9614(83)90048-4

[42] Subha, M.C.S. and Rao, K.C. (1988) Excess Volume and Viscosity of Propionic Acid in Methanol, Ethanol, 1-Propanol and 1-Butanol. Physics and Chemistry of Liquids, 18, 185-193. https://doi.org/10.1080/00319108808078593

[43] Assarsson, A. and Eirich, F.R. (1968) Properties of Amides in Aqueous Solution. I. Viscosity and Density Changes of Amide-Water Systems. An Analysis of Volume Deficiencies of Mixtures Based on Molecular Size Differences (Mixing of haRd Spheres). The Journal of Physical Chemistry, 72, 2710-2719. https://doi.org/10.1021/j100854a004

[44] Muller, E.A. and Rasmussen, P. (1991) Densities and Excess Volumes in Aqueous Poly (Ethylene Glycol) Solutions. Journal of Chemical \& Engineering Data, 36, 214-217. https://doi.org/10.1021/je00002a019

[45] Ali, A., Hyder, S. and Tariq, M. (2005) Measurements of the Properties of Binary Mixtures of Dimethylsulphoxide (DMSO) with 1-Alkanols (C4, C6, C7) at 303.15. Journal of Thermophysics, 26, 1537-1548. https://link.springer.com/article/10.1007\%2Fs10765-005-8102-9\#citeas https://doi.org/10.1007/s10765-005-8102-9

[46] Gill, D.S. and Cheema, T.S. (1983) Preferential Solvation of Ions in Mixed Solvents: I. Conductance and Viscosity Measurements of Electrolytes in N,N-Dimethylforamide + Acetonitrile Mixtures at $25^{\circ} \mathrm{C}$. Zeitschrift für Physikalische Chemie, 134, 205. https://www.degruyter.com/document/doi/10.1524/zpch.1983.134.2.205/html

[47] Marcus, Y. (1985) Ion Solvation. Wiley, New York. https://scholar.google.com/scholar?cites $=3854133641470745768 \&$ as_sdt $=2005 \&$ scio $\underline{\mathrm{dt}=0,5 \& \mathrm{hl}=\mathrm{hi} \& \mathrm{scioq}=\text { Y.+Marcus, }+ \text { Ion }+ \text { Solvation }+(\text { Wiley },+ \text { New }+ \text { York },+1985)}$

[48] Kiyohara, O. and Benson, G.C. (1979) Thermodynamic Properties of Binary Mixtures Containing Ketones III. Excess Enthalpies of $n$-Alkanes + Some Aliphatic Ketones. The Journal of Chemical Thermodynamics, 11, 453-460. https://doi.org/10.1016/0021-9614(79)90123-X

[49] Rai, R.D., Shukla, R.K., Sukla, A.K. and Pandey, J.D. (1989) Ultrasonic Speeds and Isentropic Compressibilities of Ternary Liquid Mixtures at $(298.15 \pm 0.01) \mathrm{K}$. The Journal of Chemical Thermodynamics, 21, 125-129. https://doi.org/10.1016/0021-9614(89)90122-5

[50] Koneti, A.K. and Chintalapati, S. (2014) Speeds of Sound and Excess Molar Volume for Binary Mixture of 1,4-Dioxane with 1-Heptanol at Five Temperatures. Hindawi Publishing Corporation, London, 1-7. https://doi.org/10.1155/2014/343012 